\title{
A CONSTITUTIVE MODEL FOR THE DEBRIS FLOW EROSION OF SLOPE SOIL
}

\author{
ZHAO, J.-K.* - WANG, D. - SONG, W.-B. \\ College of Engineering, Nanjing Agricultural University, Nanjing 210031, China \\ *Corresponding author \\ e-mail: jikunzhao_2006@163.com \\ (Received 22 $2^{\text {nd }}$ Apr 2019; accepted 11 $1^{\text {th }}$ Jul 2019)
}

\begin{abstract}
In this study, a constitutive model for debris flow erosion of slope soil under the influence of barriers was derived and established based on the Bingham Model theory. The upper reaches of the Laoshan were used as a study case to build an indoor slope model and simulate the debris flow erosion of slopes. Debris flow velocity, soil erosion patterns and extent of accumulation were analyzed. The results indicated that without a barrier, debris flows maintained an accelerated motion, and loose particles moved under the action of shearing strength and subsequent slope surface erosion. Accumulation was observed as overlapping stacked slices. Under the influence of barriers, debris flows were separated and blocked, which resulted in the reduction of the velocity and quality of the moving body with two symmetrical bodies formed in the accumulation area. When the barrier was placed in a high position, debris flows were distributed early and the new velocities and impacts were smaller. Furthermore, the solids carrying capacity decreased and the slope soil depths in the most in-depth sections of the erosion pit were less variable. Therefore, the erosion competency was relatively weak, which provided better protection to the downstream slope soil.
\end{abstract}

Keywords: Laoshan area, shearing strength, barrier, soil erosion depths, slope surface

\section{Introduction}

Debris flows are very destructive geological disasters. Due to their shearing strength, loose materials also move, which creates secondary disasters induced by erosion. Construction projects are often destroyed. Moreover, people's lives and property safety are threatened. Therefore, it is necessary to research the mechanisms of rainfall-induced debris flows, which can facilitate a better understanding of these disasters. These models can be used to forecast, prevent, and mitigate disasters. Thus far, research on debris flow processes have focused on numerical simulations and experiments.

International scholars have established a dynamic model for debris flows based on the SH theory. For example, the DAN calculation model was proposed by Hungr and McDougall (Hungr, 2008; Hungr and McDougall, 2009), which assumes that resistance includes internal and slope resistance and considers internal forces and erosion. The model represents different motion states and the simplified model has been verified with multiple inversion analysis. He et al. (2007) studied the initiation mechanisms for corroding to a ditch using numerical simulations. The authors also discussed the influence of factors on initial velocities, such as gravity, falling gradient, and soil strength. Fan et al. (2010) simulated dynamic entrainment processes, and they found that entrainment could increase the volume of debris flow motion, making debris flows more destructive. Based on Bingham rheological theory, Zhang et al. (2012) built a debris flow model and simulated gully bed evolution to explore bed erosion deposition processes. Wang (2001) established an energy theory for debris flow movement. He also derived a theoretical formula to determine average velocity, 
which was verified by experiments. Based on small flume experiments, Liu (2006) found that under specific experimental parameters, the regression equations for velocity and range resulted in both velocity and deposition range ratios. Lin et al. (2013) used experiments to explore debris flow deposition laws over erodible beds with changes in debris flow intensity, the total amount of debris flow, channel slope, and bed material density. Han et al. (2012) examined the Lian Hua-xin and Niujuan gullies to discuss the erosion and development and evolution features of slope and gully debris flows, respectively.

Setting barriers can be an effective measure to control debris flow processes. Based on simulations and experiments, many scholars (Ma et al., 2007; Fan et al., 2010; Huang and Lu, 2013; Prieto et al., 2018) discussed barrier effects on debris flow motion. Zhou et al. (2013) conducted model tests to explore the effect of anchor-slope protection in preventing slope debris flows and macro-meso mechanisms of soil deformation. Zhao et al. (2015) studied slope sliding and debris flow evolution with and without barriers. Those studies suggest that bank erosion increases the mass and density of the debris flow.

Many studies have found that debris flows separate when passing through a barrier (Langhans et al., 2017; Zhang et al., 2018; Lee and Jeong, 2018; Ugelvig and Egholm, 2018). The barrier position and rotation angle could change the deposition areas. When the rotation angle is equal to the critical value or exceeds it, parts of debris flow are blocked, and deposition areas drastically decrease. However, most researchers have focused on the deposition process and have rarely considered the barrier effect on velocity and slope soil erosion depths. Deposition areas are often centralized places where people live in mountainous areas. The deposition range is an important parameter to categorize dangerous areas. However, research that combines deposition range and the characterization of parameters such as velocity and erosion depths in slope soil is limited. Therefore, it is challenging to analyse disaster mechanisms and risks from debris flows systematically.

At present, most experimental studies are strongly empirical, and the applicable scope of the regression formula needs further validation, which is a challenge because of their complexity in composition and variability of dynamical processes. In addition, studies combining constitutive theories on the erosion process with laboratory experiments are few.

This study derived and established a constitutive model for the evolution of debris flows with and without barriers based on the Bingham Model theory. An indoor slope model was built to experimentally simulate debris flow erosion of slope soil. The constitutive model was validated using the experimental results gathered through inversion analysis.

\section{Material and Methods}

The model includes the viscous force, turbulence intensity within the slurry, and friction and collision force between the particles during energy transfer. Slurry and slope properties, including the roughness of soil surface, are incorporated. The turbulence power of the debris flow can be ignored because of its significant viscosity. The simplified Bingham model is adopted: 


$$
\tau=\tau_{B}+\eta \frac{d v}{d y}
$$

where, $\tau$ is shearing strength, $\tau_{B}$ is yield shearing strength, $\eta$ is the coefficient of viscosity, and $d v / d y$ is the velocity gradient in the y direction.

Influencing factors, such as the concentration of debris flow, distribution of particle size, and slope, are considered. The Manning equation is used in the velocity equation; the starting velocity is expressed as follows (Shu and Fei, 2003):

$$
v_{0}=1.62\left[\frac{S_{v}\left(1-S_{v}\right)}{d_{10}}\right]^{\frac{2}{3}} h^{\frac{1}{3}} J^{\frac{1}{6}}=1.62 B h^{\frac{1}{3}} J^{\frac{1}{6}}
$$

where, $S_{v}$ is the volume concentration of debris flow, $d_{10}$ is the lower limit of particle size, $h$ is the depth of mud, and $J$ is the slope. Eq. (2) has been verified using measured data from Jiangjia Gully and Hunshui Gully.

\section{Constitutive model of debris flow erosion on soils without barriers}

Debris flows are influenced by the friction resistance from the slope surface and internal viscous forces as they start to move. The slope surface resistance and quality of the landslide body from ${ }^{t_{i-1}}$ to ${ }^{t_{i}}$ can be expressed as:

$$
\left\{\begin{array}{l}
f_{i}=\mu_{0}\left(m_{i-1}+\frac{d m}{d t} \Delta t\right) g \cos \beta \\
m_{i}=m_{i-1}+\frac{d m}{d t} \Delta t \\
\Delta t=t_{i}-t_{i-1}
\end{array}\right.
$$

where, $\mu_{0}$ is the friction coefficient of the slope surface, $\beta$ is the slope of the flowing area, $d m / d t$ is the velocity of the quality change, $g$ is gravitational accelerations, $f_{i}$ and $m_{i}$ are resistance from slope surface and quality of debris flow at time ti, respectively. Moreover, $\Delta t$ is the time that the debris flow is moving, $i=1,2,3 \ldots$.

From $t_{i-1}$ to ${ }^{t_{i}}$, the laws of conservation of energy are:

$$
\left\{\begin{array}{l}
\frac{1}{2} m_{i-1} v_{i-1}{ }^{2}+m_{i-1} g\left(Y-y_{i-1}\right)-m_{i} g\left(Y-y_{i}\right)-\frac{1}{2} m_{i} v_{i}^{2}=W_{f}\left(t_{i-1} \sim t_{i}\right)+W_{s}\left(t_{i-1} \sim t_{i}\right) \\
W_{f}\left(t_{i-1} \sim t_{i}\right)=\mu_{0} g \cos \beta \int_{t_{i-1}}^{t_{i}}\left(m_{i-1}+\frac{d m}{d t} t\right) d t
\end{array}\right.
$$

where, $v_{i}$ is the velocity at time ti, $Y$ is the initial height of the debris flow, $W_{f}\left(t_{i-1} \sim t_{i}\right)$ and $W_{s}\left(t_{i-1} \sim t_{i}\right)$ are energy consumptions to overcome resistance and 
viscous forces from the slope surface, respectively. The formula is the typical expression of the work of cohesion from $t^{t_{-1}}$ to ${ }^{t_{i}}$.

According to another expression of energy (Huang and Lu, 2013):

$$
E_{i}=h_{c i}+\frac{v_{i}^{2}}{2 g}
$$

The energy consumption of debris flow from ${ }^{t_{i-1}}$ to ${ }^{t_{i}}$ is:

$$
\Delta E=h_{c i-1}-h_{c i}+\frac{v_{i-1^{2}}-v_{i}^{2}}{2 g}
$$

where, $h_{c i}$ is the height of center of mass of debris flow at time and $\Delta E$ is energy consumption.

After combining Eq. (4) with (6), Eq.(7) is the recursive expression about $v_{i}{ }^{2}$ :

$$
v_{i}^{2}=\frac{v_{i-1^{2}}\left(m_{i-1} g-1\right)+A m_{i-1}+B \cdot \frac{d m}{d t} \Delta t+C}{m_{i-1} g+g \cdot \frac{d m}{d t} \Delta t-1}
$$

where, $A, B$, and $C$ are expressed as $2 g^{2}\left(y_{i}-y_{i-1}\right), 2 g^{2}\left(y_{i}-Y\right)$, and $2 g\left(h_{c i}-c_{i-1}\right)$, respectively.

When $i=1$, the common expression for $v_{t}^{2}$ can be obtained:

$$
v_{t}^{2}=\frac{v_{0}^{2}\left(m_{0} g-1\right)+2 m_{0} g^{2} y+2 g^{2}(y-Y) \frac{d m}{d t} \cdot t+C_{1}}{m_{0} g+g \cdot \frac{d m}{d t} \cdot t-1}
$$

where, $C_{1}$ is $2 g\left(h_{c t}-h_{c 0}\right), t$ is time, and ${ }^{y}$ is the y intercept.

A new equation for shearing strength can be obtained by substituting the derivation of Eq. (8) into Eq. (1):

$$
\tau=\tau_{B}+\eta \frac{m_{t} g^{2}}{\left(m_{t} g-1\right) v_{t}}
$$

where, $m_{t}$ and $v_{t}$ are the quality and velocity of debris flow at time ${ }^{t}$, respectively.

Similarly, the cohesion power from 0 to $t$ can be obtained from the law of conservation of energy:

$$
W_{s}(0 \sim t)=\frac{1}{2} m_{0} v_{0}^{2}+m_{0} g Y-m_{t} g(Y-y)-\frac{1}{2} m_{t} v_{t}^{2}-\mu_{0} g \cos \beta \int_{0}^{t}\left(m_{0}+\frac{d m}{d t} \cdot t\right) d t
$$




\section{Constitutive model of debris flow erosion on soils with barriers}

The barrier is designed as an equilateral triangular prism to simplify the calculation. The length of the waist and bottom sides are $l_{0}$ and $l_{1}$, respectively. The safety height is $H$, regardless of the displacement and overflow over the barrier under the impact of the debris flow.

The barrier is fixed on the central axis of the slope (Figure 1) to reduce the variables' interference on the constitutive model based on the barrier position. The distance from the barrier to the side of the plat is $x_{1}$ (note: the physical quantities without vector symbols are scalars, such as $\mathrm{t}_{1}$ and $\mathrm{x}_{1}$ ). The energy consumption to overcome the friction from the barrier is ignored, because the roles for shunting and obstructing are stronger than the buffering role.

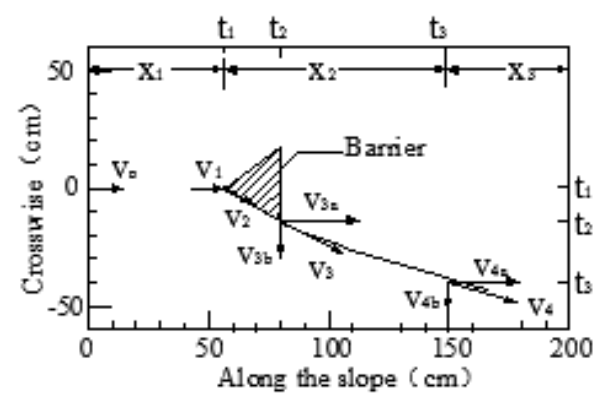

Figure 1. Velocity diagram for a barrier on the axis of the slope

The movement before a debris flow contacts the barrier is the first phase, followed successively by movement along the barrier and after separating from it.

According to the decomposition principle for velocity, ${ }^{v_{1}}$ is decomposed into two symmetrical components at time $t_{1}$ (Figure $2 a$ ):

$$
v_{2}=\frac{v_{1}}{2 \cos \frac{\theta}{2}}
$$

where, $\theta$ is the apical angle of the triangle.

Similarly, the quality has an equal distribution:

$$
m_{2}=\frac{1}{2} m_{1}
$$

From ${ }^{t_{1}}$ to ${ }^{t_{2}}$, the law of conservation of energy can be expressed as follows:

$$
\left\{\begin{array}{l}
\frac{1}{2} m_{2} v_{2}^{2}+m_{2} g\left(Y-y_{2}\right)-\frac{1}{2} m_{3} v_{3}^{2}-m_{3} g\left(Y-y_{3}\right)=W_{f}\left(t_{1} \sim t_{2}\right)+W_{s}\left(t_{1} \sim t_{2}\right) \\
m_{3}=m_{2}+\frac{d m}{d t}\left(t_{2}-t_{1}\right) \\
W_{f}\left(t_{1} \sim t_{2}\right)=\mu_{0} g \cos \beta \int_{t_{1}}^{t_{2}}\left(m 2+\frac{d m}{d t} t\right) d t
\end{array}\right.
$$


where, $v_{j}, m_{j}$ and ${ }^{y_{j}}$ are velocity, quality and ${ }^{y}$ intercept after separating from the barrier at time $t_{j-1}$, respectively. Wherein, $j=2,3 \ldots \ldots$

$$
v_{3}^{2}=\frac{v_{2}^{2}\left(m_{2} g-1\right)+A m_{2}+B \cdot \frac{d m}{d t}\left(t_{2}-t_{1}\right)+C}{m_{2} g+g \cdot \frac{d m}{d t}\left(t_{2}-t_{1}\right)-1}
$$

where, $A, B$ and $C$ are expressed as $2 g^{2}\left(y_{3}-y_{2}\right), 2 g^{2}\left(y_{3}-Y\right)$, and $2 g\left(h c_{3}-h_{c 2}\right)$, respectively; $h_{c j}$ is the height of the center of mass of debris flow at time $t_{j-1}$.

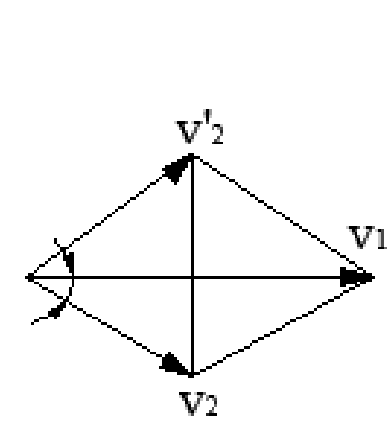

(a)

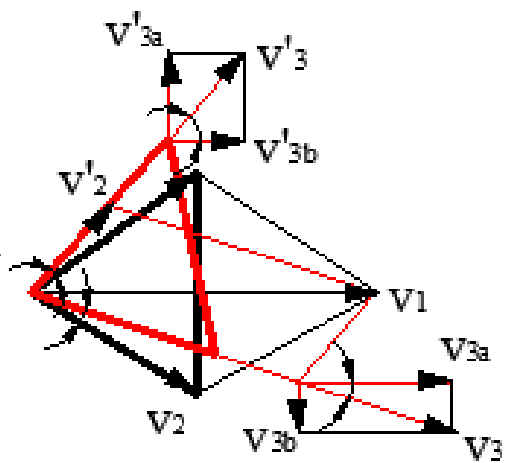

(b)

Figure 2. Velocity diagrams for a barrier on the slope: (a) along the axial; (b) Rotated $\phi$

From $t_{2}$ to ${ }^{t 3}$, the trajectory of the debris flow is approximately a parabola. The slope surface resistance consists of resistance on the slope axis direction and lateral resistance. The law of conservation of energy can be expressed as follows:

$$
\left\{\begin{array}{l}
\frac{1}{2} m_{3} v_{3}^{2}+m_{3} g\left(Y-y_{3}\right)-\frac{1}{2} m_{4} v_{4}^{2}-m_{4} g\left(Y-y_{4}\right)=W_{f}\left(t_{2} \sim t_{3}\right)+W_{s}\left(t_{2} \sim t_{3}\right) \\
m_{4}=m_{3}+\frac{d m}{d t}\left(t_{3}-t_{2}\right) \\
W_{f}\left(t_{2} \sim t_{3}\right)=\left(\mu_{0}+\mu_{1}\right) g \cos \beta \int_{t_{2}}^{t_{3}}\left(m_{3}+\frac{d m}{d t} t\right) d t
\end{array}\right.
$$

where, ${ }^{\mu 1}$ is coefficient of friction of lateral resistance.

The velocity after separating from the barrier at time ${ }^{t_{3}}$ can be obtained by combining Eq. (14) with Eq. (15):

$$
v_{4}^{2}=\frac{v_{3}^{2}\left(m_{3} g-1\right)+A m_{3}+B \cdot \frac{d m}{d t}\left(t_{3}-t_{2}\right)+C}{m_{3} g+g \cdot \frac{d m}{d t}\left(t_{3}-t_{2}\right)-1}
$$


where, $A, B$, and $C$ are expressed as $2 g^{2}\left(y_{4}-y_{3}\right), 2 g^{2}\left(y_{4}-Y\right)$, and $2 g^{2}\left(y_{4}-Y\right)$, respectively.

Higher values of $\theta$ result in longer lateral distances. Thus, the scope of the 'Not erosion zone' is large, which means that the protected areas in the middle and lower reaches are broad.

A new equation for shearing strength when debris flow passes the barrier can be obtained after substituting the derivation of Eq. (16) into Eq. (1):

$$
\tau=\tau_{B}+\eta \frac{m_{P} g^{2}}{\left(m_{P} g-1\right) v}
$$

where, $m_{P}$ and $v$ are the quality and velocity of the debris flow at $t$, respectively; wherein, $m_{P}$ can be expressed as $m_{0} / 2+\left(t 3-t_{1} / 2\right) d m / d t$.

Based on these equations, the change in the barrier position and rotation angle can be quantified (Figure 3).

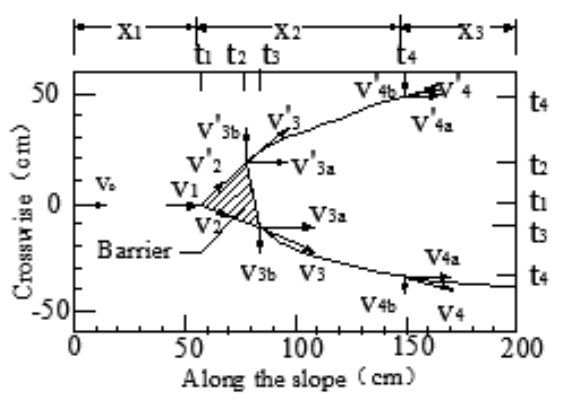

Figure 3. Velocity diagram for a barrier rotating $\phi$ degrees

Assuming that the distance from plat to the vertex of barrier is fixed $\left(x_{1}\right)$, the degrees of counterclockwise rotation that centers the barrier vertex is $\phi$. The velocity will be decomposed into $v_{2}$ and $v^{\prime}{ }_{2}$ when the debris flow contacts the barrier according to the sine theorem:

$$
\frac{v_{1}}{|\sin (\pi-\theta)|}=\frac{v_{2}}{\left|\sin \left(\frac{\theta}{2}+\phi\right)\right|}=\frac{v^{\prime}{ }_{2}}{\left|\sin \left(\frac{\theta}{2}-\phi\right)\right|}
$$

The quality of the moving body on the left is not equal to the right under the influence of rotation. The volume is expressed as $V=\int d V=\iiint d a \times d b \times d h$, and the qualities of moving body on both sides at time ${ }^{t_{1}}$ are:

$$
\left\{\begin{array}{l}
m_{2}=\left(m_{1}-D\right) / 2 \\
m_{2}^{\prime}=\left(m_{1}+D\right) / 2
\end{array}\right.
$$


where, $D$ is $\rho \tan \phi \iiint d b \times d b \times d h$.

According to the law of conservation of energy, a left moving body from ${ }^{t_{1}}$ to ${ }^{t_{3}}$ and from ${ }^{t_{3}}$ to ${ }^{t 4}$ can be expressed as follows, respectively:

$$
\begin{aligned}
& \left\{\begin{array}{l}
\frac{1}{2} m_{2} v_{2}{ }^{2}+m_{2} g\left(Y-y_{2}\right)-\frac{1}{2} m_{3} v_{3}^{2}-m_{3} g\left(Y-y_{3}\right)=W_{f}\left(t_{1} \sim t_{3}\right)+W_{3}\left(t_{1} \sim t_{3}\right) \\
m_{3}=m_{2}+\frac{d m}{d t}\left(t_{3}-t_{1}\right) \\
W_{f}\left(t_{1} \sim t_{3}\right)=\mu_{0} \cos \beta \int_{t_{1}}^{t_{3}}\left(m_{2}+\frac{d m}{d t} t\right) d t
\end{array}\right. \\
& \left\{\begin{array}{l}
\frac{1}{2} m_{3} v_{3}{ }^{2}+m_{3} g\left(Y-y_{3}\right)-\frac{1}{2} m_{4} v_{4}{ }^{2}-m_{4} g\left(Y-y_{4}\right)=W_{f}\left(t_{3} \sim t_{4}\right)+W_{s}\left(t_{3} \sim t_{4}\right) \\
m_{4}=m_{3}+\frac{d m}{d t}\left(t_{4}-t_{3}\right) \\
W_{f}\left(t_{3} \sim t_{4}\right)=\left(\mu_{0}+\mu_{1}\right) \cos \beta \int_{t_{3}}^{t_{4}}\left(m_{3}+\frac{d m}{d t} t\right) d t
\end{array}\right.
\end{aligned}
$$

The velocity of the left body at time ${ }^{t} 4$ after separation from the barrier can be obtained by combining Eq. (20) with Eq. (21).

$$
v_{4}{ }^{2}=\frac{v_{3}^{2}\left(m_{3} g-1\right)+A m_{3}+B \frac{d m}{d t}\left(t_{4}-t_{3}\right)+}{m_{3} g+g \cdot \frac{d m}{d t}\left(t_{4}-t_{3}\right)-1} C
$$

where, $A, B$, and $C$ are expressed as $2 g^{2}\left(y_{4}-y_{3}\right), 2 g^{2}\left(y_{4}-Y\right)$, and $2 g\left(h_{c 4}-h_{c 3}\right)$, respectively.

Identically, a new formula for the shearing strength of the left moving body at time $t$ can be expressed as follows:

$$
\tau=\tau_{B}+\eta \frac{m \mathrm{~g}^{2}}{\left(m_{\mathrm{l}} \mathrm{g}-1\right) v}
$$

where, $m_{l}$ is $\left(m_{0}-D\right) / 2+(d m / d t)\left(t-t_{1} / 2\right)$.

Similarly, the velocity of the right body at the same time is:

$$
v^{\prime}{ }_{4}^{2}=\frac{v^{\prime}{ }^{2}\left(m^{\prime}{ }_{3} g-1\right)+A m^{\prime}{ }_{3}+B \frac{d m}{d t}\left(t_{4}-t_{2}\right)+C}{m^{\prime}{ }_{3} g+g \cdot \frac{d m}{d t}\left(t_{4}-t_{2}\right)-1}
$$

where, $A, B$, and $C$ are expressed as $2 g^{2}\left(y^{\prime}{ }_{4}-y^{\prime}{ }_{3}\right), 2 g^{2}\left(y_{4}^{\prime}-Y\right)$, and $2 g\left(h_{c 4}^{\prime}-h_{c 3}^{\prime}\right)$, respectively. 
The shearing strength of the right moving body at the same time is:

$$
\tau=\tau_{B}+\eta \frac{m_{r} g^{2}}{\left(m_{r} g-1\right) v}
$$

where, $m_{r}$ can be expressed as: $\left(m_{1}+D\right) / 2+(d m / d t)\left(t-t_{1}\right)$

The adjusted rheological model under the influence of a barrier is identical to the condition without it. Therefore, the shearing strength can be expressed as:

$$
\tau=\tau_{B}+\eta \frac{m g^{2}}{(m g-1) v}
$$

The qualities with the three conditions can be deduced as followings:

$$
m= \begin{cases}m_{0}+\frac{d m}{d t} t & \text { (without barrier) } \\ \frac{m_{0}}{2}+\frac{d m}{d t}\left(t_{3}-\frac{t_{1}}{2}\right) & \text { (barrier rotates along axies) } \\ \frac{m_{0}-D}{2}+\frac{d m}{d t}\left(t-\frac{t_{1}}{2}\right) & \text { (body on left side) } \\ \frac{m_{0}+D}{2}+\frac{d m}{d t}\left(t-t_{1}\right) & \text { (body on right side) }\end{cases}
$$

Without a barrier, debris flows accelerate motion under the resultant force. According to $E q$. (8), the impact force increases along with the ever-increasing quality, and the capacity to erode slope soil increases. However, the overall shearing strength decreases as a result of weak liquidity. As a result, the erosion depths shallow. After setting a barrier, debris flows will be separated as they make contact with it. Comparing $E q$. (8) with Eq. (22), the velocity with a barrier is much smaller than others. The acceleration decreases along with a decrease in quality, and the impact decreases. Eventually, slope soil erosion downstream weakens.

\section{Results}

Figure 4 shows a plan view map of the Laoshan area in Nanjing, China, the study area. It locates at $32^{\circ} 07^{\prime} 3.55^{\prime \prime} \mathrm{N}$ and $118^{\circ} 37^{\prime} 42.30^{\prime \prime} \mathrm{E}$. The area of interest trend is from southwest to northeast and the western section is higher and steeper than other areas. As shown in Figure 5, the mountain profile consists of bed rock on the bottom, the gravel layer and the soil layer. The layer thickness ration is about 3:2:9. Most area of the slope are steep, from 30 to 60 . It has a high incidence of debris flow under rainfall that will clog roads and other construction facilities.

\section{Configuring the indoor soil model}

A $2.1 \mathrm{~m}$ long, $4 \mathrm{~m}$ wide, and $2 \mathrm{~m}$ high slope soil model was built inside (Figure 6). The reduced scale represents the natural proportions of the soil structure. A 30-cm-thick bevel face with a gradient of $5^{\circ}$ was built on the bottom as the bedrock using cement 
mortar. The model soil slope was composed of a 20-cm-deep sand stratum with an overlying 90-cm-deep soil stratum. There is a flat crest at the top and flat base near the toe of the slope. The flat base is fully open. In addition, a $1.93 \mathrm{~m}$ long, $0.5 \mathrm{~m}$ wide, and $0.4 \mathrm{~m}$ high storage tank was placed on the flat crest. The storage tank had a $30^{\circ}$ slope inside which could accommodate $0.386 \mathrm{~m}^{3}$ slurry that could be released all at once. When the door opened, the slurry flowed along the ramp way.

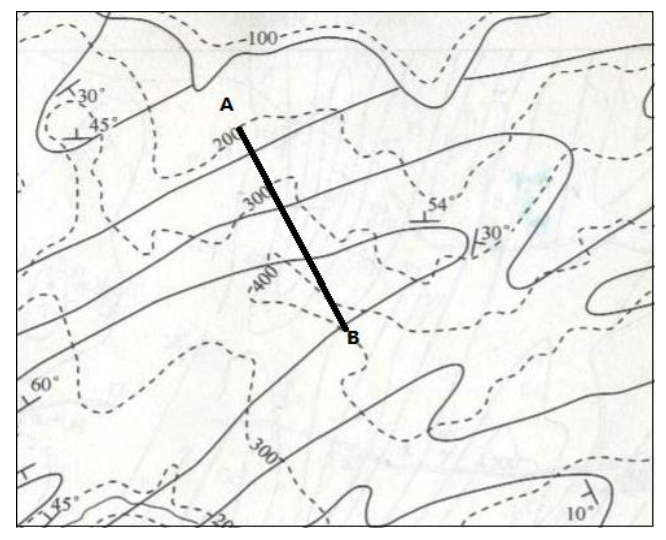

Figure 4. Plan view map of the study area $(1: 25000)$

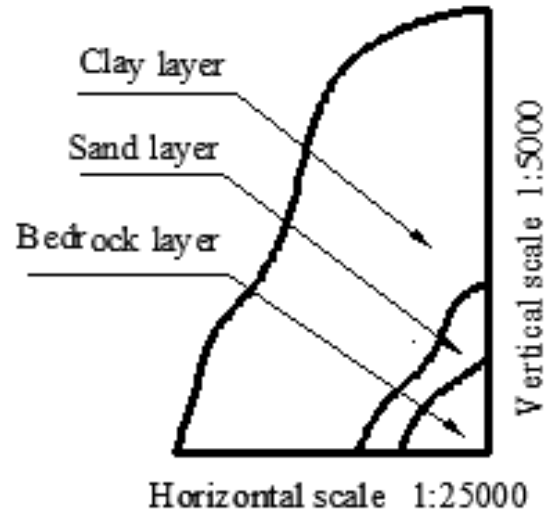

Figure 5. Exploration section line map

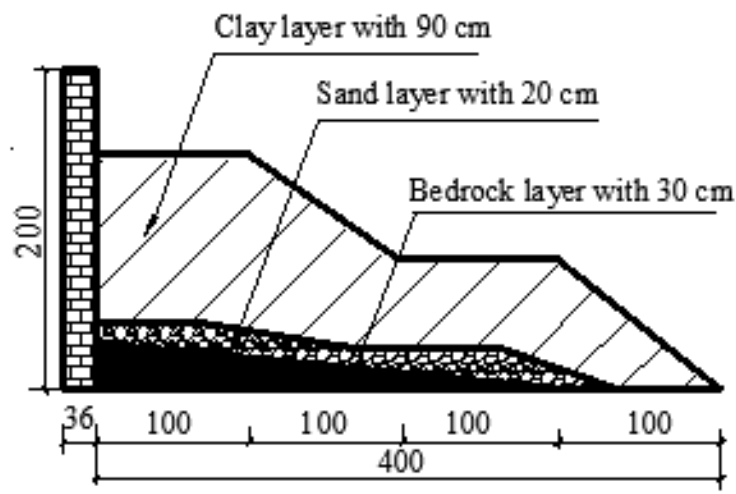

Figure 6. Cross-section of the model slope indicating the thicknesses of each stratum

The model slope was fully consolidated under natural conditions in order that the soil was returned to the pre-disturbance state. The soils used in the model experiments were collected from the research area to maintain natural conditions. Before each test, various monitoring indicators were measured. Experiments began once each index indicated essential stability. And embedded probes were placed at eight monitoring locations on the upper and lower layers, as shown in Figure 7. Points 1 and 4 were on the middle of the platform; points 2 and 5 were on the side edges; points 3 and 6 were in the middle of the slope; and points 7 and 8 were near the toe.

After scaling, soils from the corresponding locations in the study area were collected to test the mechanical properties. Slope sliding and the debris flow detection system was determined to measure the shearing strength of the experimental and undisturbed soils (Figure 8). The shearing strength of the undisturbed soils in the upper layer was higher 
than that in the lower layer. According to Figure 8, the shearing strength at monitoring points 1, 2, 3, and 8 plotted along line. Based on these results, the shearing strengths of experimental soils were close to those of the undisturbed soils. Therefore, the accuracy of the model was guaranteed.
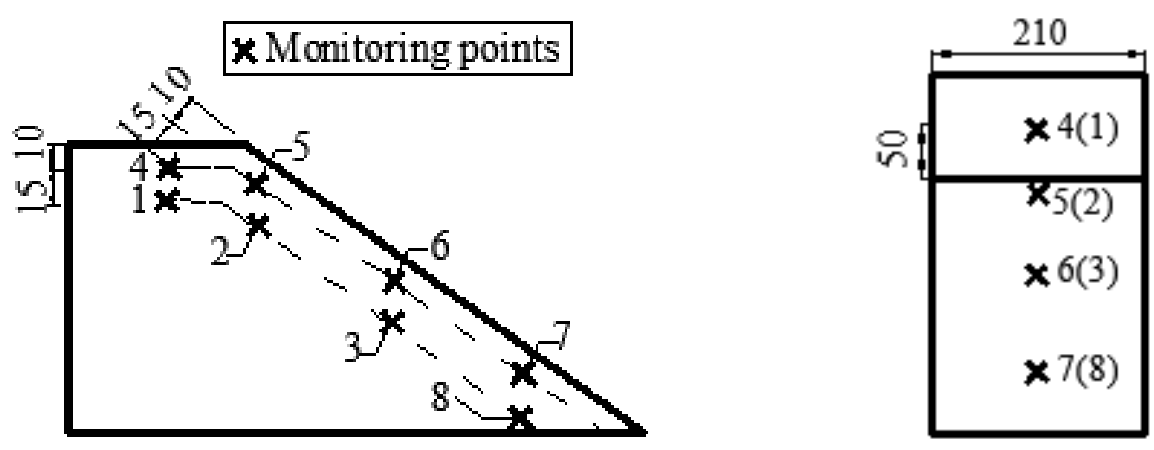

Figure 7. Locations of monitoring points:(a) side view; (b) top view

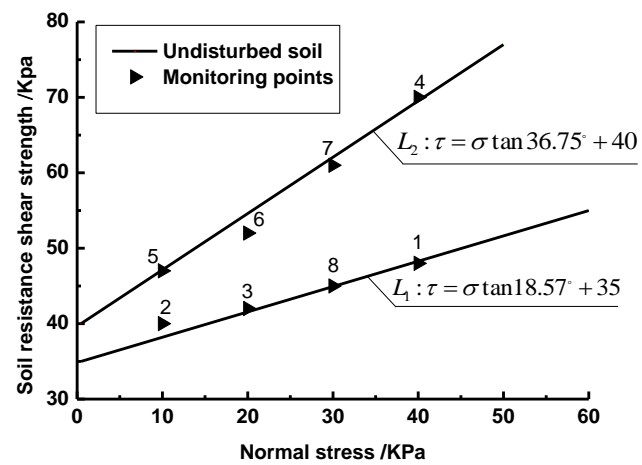

Figure 8. Lines of shear strength

Based on soil thickness and the maximum erosion depth without a barrier, a 30-cmhigh barrier to form a 'Not erosion zone' was used in the experiments. Along the bottom, each side was $30 \mathrm{~cm}$ long and it was buried $10 \mathrm{~cm}$ deep in the soils. The barrier positions and rotation angles on the model slope are shown in Figure 9.

Figure 10 shows the coordinates used in the experiments. The debris flow process induced by rainfall on a $200-\mathrm{cm}-$ long slope with a $45^{\circ}$ slope was studied. The slope was $140 \mathrm{~cm}$ high and $140 \mathrm{~cm}$ wide (horizontal), with observation points at $7 \mathrm{~cm}$ intervals starting at 0 on the $\mathrm{Y}$ coordinate axis.

The density of slurry was $20.1 \mathrm{kN} / \mathrm{m}^{3}$. A $45^{\circ}$ slope was used for the movement area. The barriers were placed at $\mathrm{L} / 3$ and $\mathrm{L} / 2$ ( $\mathrm{L}$ is the length of slope) along the slope, and barriers' rotation angles of $0^{\circ}$ and $15^{\circ}$ along axis were considered. Several trials were performed under these four conditions. Table 1 shows the set of variables for each condition category.

\section{Analysis of debris flow evolution}

In the experiment, debris flows began with a nonzero initial velocity, and the velocity along the slope was faster than other directions, as shown in Figure 11. The gravity, 
slope friction and internal viscous force changed as the amount of solid material carried along the slope increased. Particle separation was generated during the process due to the incorporation of large particles, which hindered an increase of velocity. This resulted in a nonlinear acceleration curve and overall change in shearing strength of the debris flow.

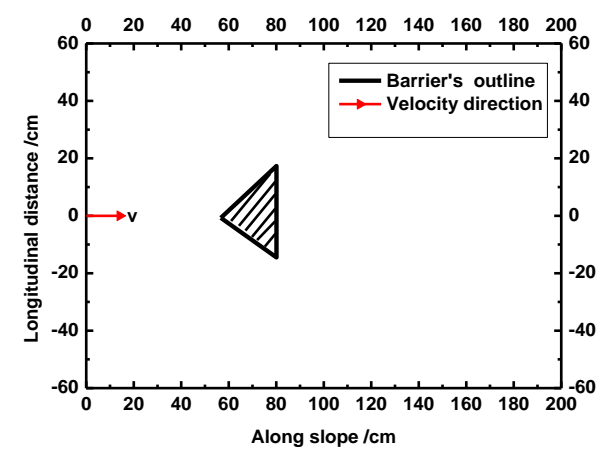

(a)

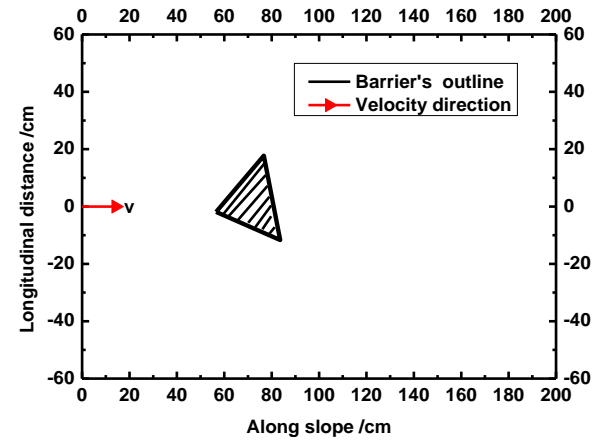

(b)

Figure 9. Schematic diagram of the barrier positions and rotation angles:(a) barrier without rotation; (b) barrier rotated $\phi$

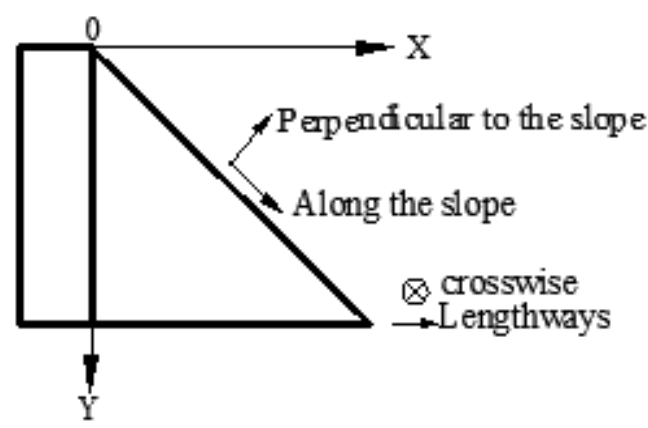

Figure 10. Schematic diagram showing the coordinate directions

Table 1. Variables for each condition

\begin{tabular}{|c|c|c|c|c|}
\hline \multirow[b]{2}{*}{ Conditions } & \multirow{2}{*}{$\begin{array}{c}\text { Density } \\
\left(\mathbf{k N} / \mathbf{m}^{3}\right)\end{array}$} & \multirow{2}{*}{$\begin{array}{c}\text { Slope } \\
\left({ }^{\circ}\right)\end{array}$} & \multicolumn{2}{|c|}{ Barrier } \\
\hline & & & Position & $\begin{array}{c}\text { Angle } \\
\left({ }^{\circ}\right)\end{array}$ \\
\hline Condition I & 20.1 & 45 & no & no \\
\hline Condition II & 20.1 & 45 & $\mathrm{~L} / 3$ & no \\
\hline Condition III & 20.1 & 45 & $\mathrm{~L} / 3$ & 15 \\
\hline Condition IV & 20.1 & 45 & $\mathrm{~L} / 2$ & 0 \\
\hline
\end{tabular}

According to the experimental and calculated results, curves showing the relationships between velocity and time were generated, as shown in Figure 12. Conditions (II), (III), and (IV) were used to evaluate the right side of the flow surface. Based on the $v-t$ curve and calculations, the relationship between shearing strength and time is shown in Figure 13. 


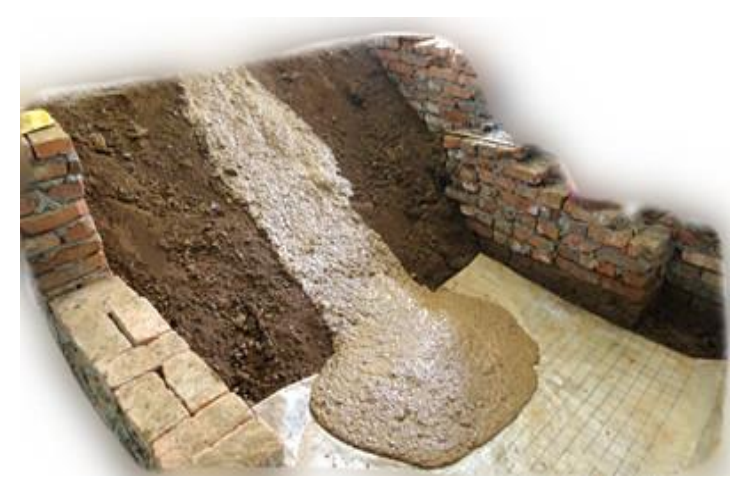

Figure 11. Debris flow patterns

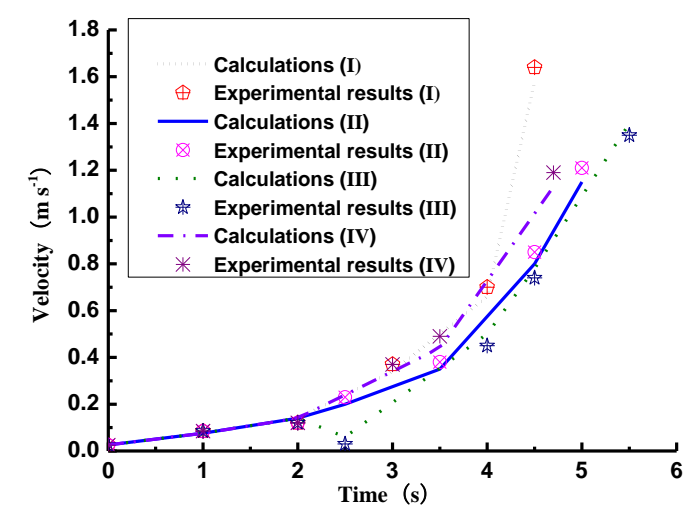

Figure 12. Velocity-time curves for different conditions

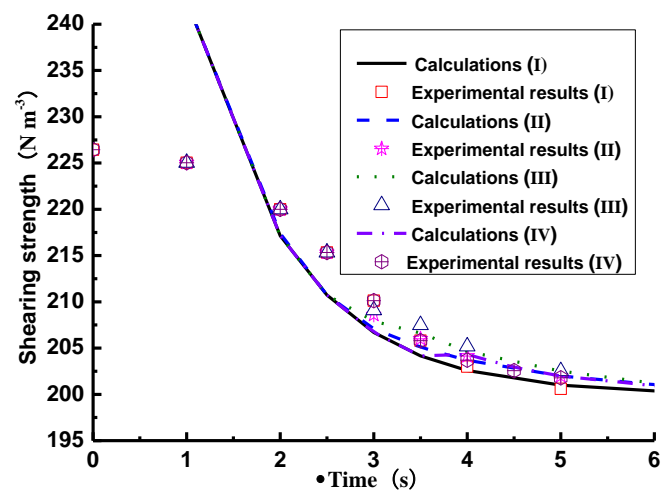

Figure 13. Shearing strength-time curves for different conditions

Figure 12 shows that under Condition (I), the debris flows showed accelerated motion with a nonzero initial velocity, with $2 \mathrm{~s}$ and $4 \mathrm{~s}$ as significant turning points. Loose material was carried by shearing strength along the slope surface, with an increasing impact force. The erosion capacity was enhanced and the velocity reached a peak of $1.6 \mathrm{~m} / \mathrm{s}$, when the debris flow arrived at the toe of the slope at $4.5 \mathrm{~s}$. Comparing Conditions (I), (II) and (III) in Figure 13, after contacted with the barrier at $2 \mathrm{~s}$, the velocity decreased. The velocity of Condition (II) was almost constant at $2.5 \mathrm{~s}$, because 
the decomposition generated it under a force equal to the fundamental force. However, the acceleration decreased with a reduction in quality, reaching a lower velocity at the same time as Condition (I). Under Condition (III), the barrier diversion decreased the velocity $0.1 \mathrm{~m} / \mathrm{s}$ at $2.5 \mathrm{~s}$, and velocity of rotation (right side) was significantly faster than the other side (Figure $2 b$ ). Simultaneously, the quality also changed so that it was more extensive on the right side. The slower the 'initial velocity', the lower the kinetic energy, and weak soil erosion was confirmed in both the calculations and experimental results.

Comparing Conditions (II) and (IV) in Figure 12, when the barrier was close to the toe of slope, the original movement pattern was maintained longer and contact with the barrier was later. Under condition (II), the debris flow began a new accelerated motion when it made contact with the barrier at $2 \mathrm{~s}$. The velocity under Condition (I) was the same as under Condition (IV) and both were greater than the acceleration under Condition (II) from $2 \mathrm{~s}$ to $3.5 \mathrm{~s}$. The velocity under Condition (IV) reached $0.5 \mathrm{~m} / \mathrm{s}$ at $3.5 \mathrm{~s}$. This velocity was unchanged at contact with the barrier, and then accelerated along it. At this point, the maximum numerical difference in velocity between Conditions (II) and (IV) was $0.1 \mathrm{~m} / \mathrm{s}$. Subsequently, Condition (IV) was greater than Condition (II). Therefore, the impact force upstream of L/3 L/2 under Condition (IV) was greater than that under condition (II), and soil erosion in the region was significant, indicating that the protective effect of the downstream region was weaker than that in Condition (II). These conclusions were the same in both the calculations and experimental results.

Figure 13 shows a non-linear negative correlation between shearing strength and time. Comparing Figure 12 with Figure 13, four conditions reached a maximum shearing strength at $1 \mathrm{~s}$. As the debris flow process advanced, loose particles increased. In spite of the increasing velocity, the overall shearing strength decreased. The curve under Condition (I) flattened after $4 \mathrm{~s}$ and the head of the debris flow was close to the slope toe. As the liquidity worsened, the overall shearing strength weakened and approached the yield stress. Influenced by the barrier position, the velocities at the head both decreased after $2.5 \mathrm{~s}$ and $3.5 \mathrm{~s}$ under Conditions (II) and (III). The overall shearing strength declined, flattened out after $5 \mathrm{~s}$ and $6 \mathrm{~s}$, and consistently approached the yield stress. The curve of the shearing strength under Condition (III) was gentler than that under Condition (II). The overall energy consumption was large and the shearing strength decreased under the influence of the barrier. Both the ability to carry loose particles and erosion weakened. Therefore, variations in velocity and shearing strength under Condition (III) were moderate.

In summary, debris flows slowed after contact with the barrier. With quality deallocation, the impact force weakened and the surface erosion in the downstream area decreased. When the barrier was in the high position, the weakening effect was clear.

Furthermore, a greater rotation angle resulted in the experimental results were in agreement with calculations.

\section{Analysis of soil erosion depths after debris flows}

To explore the soil erosion effect on erosion depths, the right side was evaluated under Conditions (IV), (V) and (VI). Figure 14 shows the cross-sectioned positions. Based on the experimental data, variations in slope surface erosion patterns under different conditions are shown in Figure 15, which were similar under all the evaluated conditions. The upper part of the model slope was shallow, while the center at $56 \mathrm{~cm}$ 
appeared deeper than other areas. Erosion depths shallowed in the lower part of the slope. The slopes differed between the upper and lower segments: steep in the upper $\left(49.3^{\circ}\right)$ and more moderate in the lower $\left(36.5^{\circ}\right)$. Debris flows were in a state of accelerated motion in the movement area. Loose material on the pathway surface moved under the influence of shearing strength, which resulted in the surface erosion. The mechanism for erosion was an increase in the capacity of carrying solids at a certain velocity. This erosion was also associated with a reduction in overall moisture content and higher viscosity. Turbulent flow was unusual at high viscosity but could carry more surface materials away. Therefore, the erosion ability would weaken after an increase in density.

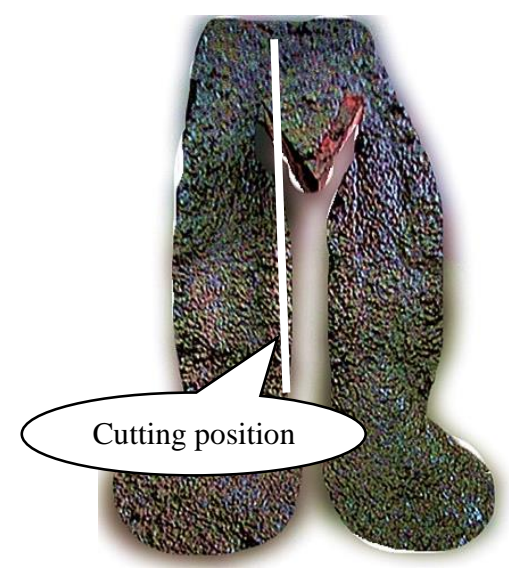

(a)

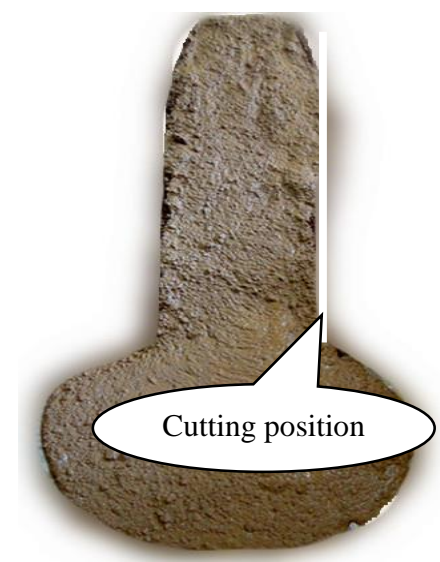

(b)

Figure 14. Cutting positions for different conditions: (a) with barrier; (b) without barrier

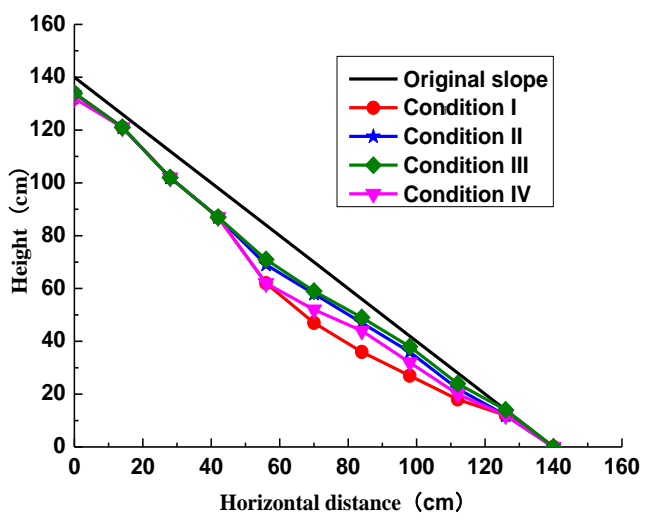

Figure 15. Variations in slope surface erosion depths for different conditions

Within the horizontal distance from 0 to $56 \mathrm{~cm}$, the depth variations were consistent for the four conditions. Soils were $5 \mathrm{~cm}$ deep from approximately 0 to $40 \mathrm{~cm}$ after erosion, and gradually deepened from 40 to $56 \mathrm{~cm}$. Depth variations under Conditions (I) and (II) were consistent and more precise than that under the other conditions. Variations were moderate under Condition (II) and most gentle under Condition (III). At a horizontal distance of $40 \mathrm{~cm}$, debris flows had a resolvable velocity and earlier quality distribution under the influence of the barrier compared to Condition (II). 
Subsequently, on both sides of the moving body, new erosion was initiated with the weak force. The overall shearing strength was small under Condition (II). Therefore erosion depths were significantly less than that under Conditions (I) and (IV). Comparing Conditions (III) and (II), the areas affected on the sides were different, induced by the barrier rotation. As a result, distributions in quality and velocity were also unequal. Although the quality under Condition (III) was greater than that under Condition (II), the overall kinetic energy was smaller. Therefore, the shearing strength was smaller and the ability to carry solid material was weaker under Condition (III). This result is shallower in the curve of erosion depths under Condition (III) than under Condition (II). In the horizontal distance from 56 to $140 \mathrm{~cm}$, the debris flow separated under the influence of the barrier under Condition (IV). Its initial kinetic energy was small and erosion ability was weak, so that the soil depths were shallower than those under Condition (I). The velocity under Condition (IV) was much larger than that under Conditions (II) and (III), hence the curve of the slope surface erosion patterns under Condition (IV) was lower than that under Conditions (II) and (III).

Based on the comparative analysis, the following conclusions were reached: a greater rotation angle resulted in a smaller 'initial kinetic energy' on the side of rotation, weaker overall shearing strength, and capacity for carrying soil. Therefore, appropriate position placement and rotation angle of the barrier will help protect downstream areas. More broadly, the slope line becomes gentle after erosion. A comparison of the experimental results with calculations is provided in Figure 12.

\section{Analysis of deposition range after erosion}

The head of the debris flow decelerates after arriving at the horizontal plane, while the tail maintains acceleration. However, the tail decelerated rapidly after reaching the ramp exit. Figure 12 shows the deposition range under different conditions.

When the head of the debris flow reached the slope toe, the velocity peaked. Deposition began when the slope decreased. Influenced by strong friction from the ground, the power components decreased, and longitudinal velocity declined. Because the ground was flat, the boundary constraints in the horizontal direction disappeared and a transverse circulation was generated. The slurry spread and fan bodies fully developed because the flow was unobstructed. In addition, because of complex transverse momentum, the internal resistance of the slurry increased. Eventually, deposition formed under the influence of the viscous force and ground friction.

Figure 16 shows that the depositions all formed lap alluvial fans. Two alluvial fans developed under Conditions (II), (III), and (IV). When the barrier was on the centerline of the slope, this was the point of debris flow contact, which resulted in symmetric splitflows. Moreover, the deposition bodies under Conditions (II) and (IV) were approximately symmetrical.

\section{Discussion}

Comparing Conditions (II) and (IV), the single alluvial fan was narrow and long under Condition (IV), but wide and short under Condition (II). The maximum length, width, and thickness of the deposition were $52 \mathrm{~cm}, 40 \mathrm{~cm}$, and $12 \mathrm{~cm}$ under Condition (IV), respectively. The corresponding values were $86.5 \%, 125 \%$, and $142 \%$ of that under Condition (II). The deposition points of the maximum thickness under Conditions (IV) and (II) were located at the leading edge, at $28 \mathrm{~cm}$ and $35 \mathrm{~cm}$, respectively. A low 
barrier position resulted in a long acceleration time. Therefore, when it reached the horizontal plane, the vertical velocity was large, and the fan could develop fully. Therefore, the position of the maximum deposition thickness was far from the exit ramp.

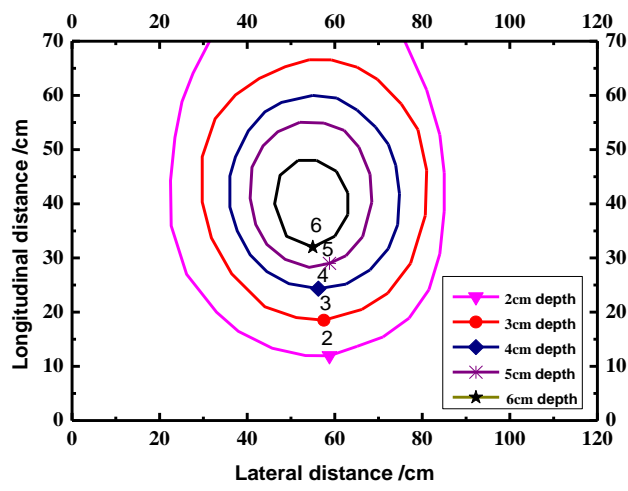

(a)

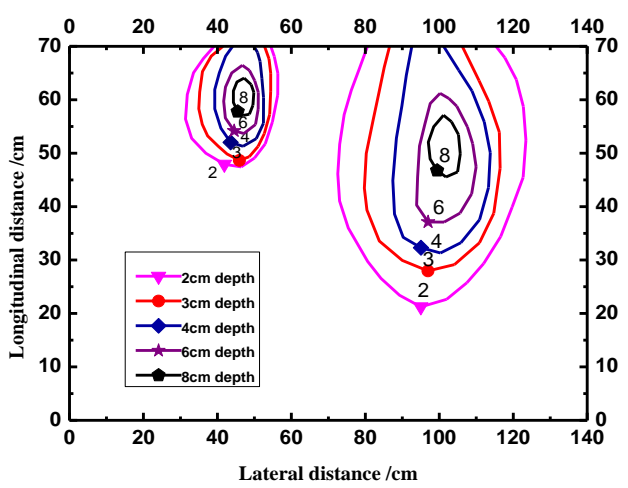

(c)

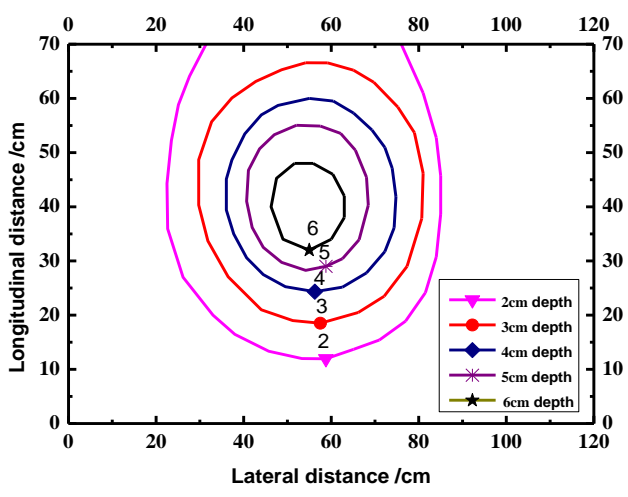

(b)

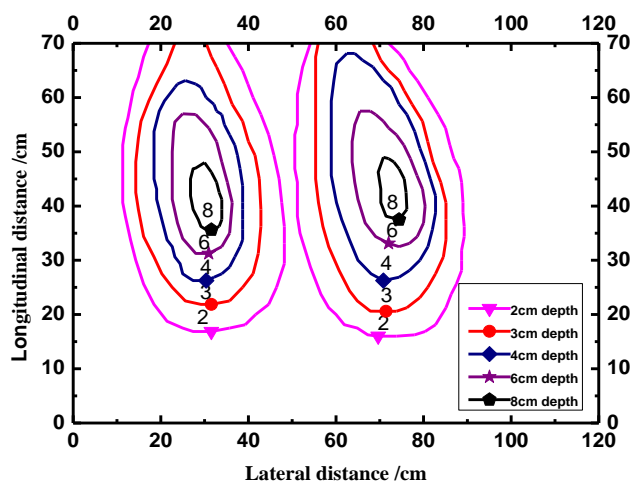

(d)

Figure 16. Accumulation under different conditions: (a) condition (I), (b) condition (II), (c) condition (III), and (d) condition (IV)

Comparing Conditions (II) and (III), the barrier rotated counterclockwise along the axis was examined. The effective contact area and quality on the right side were larger than that on the left side. The proportional change was approximately 1:2. The maximum length and width of deposition on the left under Condition (III) were $20 \mathrm{~cm}$ and $25 \mathrm{~cm}$, respectively. On the right side, the corresponding values were $5 / 2$ and $8 / 5$ times than that on the left. The deposition area was twice as large as that of the left, in agreement with the calculated values. Thus, a greater angle resulted in a more significant quality of the right moving body. The high lateral velocity component resulted in longer movement time in the lateral direction. As a result, the space between the deposition bodies was large and the quality (on the right side) of the deposition body on the rotating direction (reverse) was high. The results also showed that the deposition area ratio was approximately equal to the quality ratio between the left and right for the moving body. 


\section{Conclusions}

This study derived and established a constitutive model for slope soil erosion due to the debris flow with and without barriers based on the Bingham Model theory. This constitutive model was established based on Bingham Model velocities and equations under Conditions of different barrier positions and rotations. Equations for the modified Bingham Model were provided under three Conditions.

The upper reaches of the Laoshan was used as the study case to build an indoor slope model and simulate debris flow erosion processes. The experimental results were in agreement with calculations. Based on the constitutive equations, predictions of the soil erosion depths and deposition range after erosion were more accurate. Expressions for the shearing strength were also verified through experiments.

The buffering effect improved as the barrier and edge of platform were moved closer. In these Conditions, the shearing strength weakened, and then the damage in the downstream region due to soil erosion also decreased. A greater rotation angle also weakened the damage in the direction of rotation. Therefore, interception facilities should be built on the upstream slope and the rotation angle based on the characteristics of the active region downstream should be considered. These efforts will result in the optimal interception, diversion, and weakening of slope erosion.

In future research, we will focus on the secondary disasters of debris flow because debris flow is a very destructive geological disaster. Loose material moves in response to debris flow's shearing force, thereby creating a secondary disaster induced by erosion. Rainfall is the main reason for slope instability, which leads to large-scale landslides.

Acknowledgements. The study was supported by the Special Fund of Basic Scientific Research Operations of Central Universities of China (Grant No. KYZ201664) and by the Natural Science Foundation of Jiangsu Province (Grant No. BK2010457). Their financial support is gratefully acknowledged. We thank the Associate Editor and anonymous reviewers for their helpful and insightful comments.

\section{REFERENCES}

[1] Fan, Y. Y., Wang, S. J., Wang, E. Z., Liu, X. L. (2010): Simulation analysis of dynamic process of entrainment of path material by debris flow. - Chinese Journal of Rock Mechanics and Engineering 29(S2): 4146-4152.

[2] Han, Y. S., Huang, P., Zhu, Y. Y., Hu, K. H. (2012): Field monitoring and erosiondeposition sediment of flash-flood debris flow in suffered areas-a case study at Lianhuaxin Gully. - Journal of Hydraulic Engineering 43(S2): 133-138.

[3] He, S. M., Wu, Y., Li, X. P. (2007): Research on eroded start mechanism of channel debris flow. - Rock and Soil Mechanics 28(S1): 155-159.

[4] Huang, J. Y., Lu, T. H. (2013): Research and application of permeable arch dam in preventing projects for debris flow. - Journal of Water Resources and Architectural Engineering 11(1): 166-169.

[5] Hungr, O. (2008): Simplified models of spreading flow of dry granular material. Canadian Geotechnical Journal 45(8): 1156-1168.

[6] Hungr, O., McDougall, S. (2009): Two numerical models for landslide dynamic analysis. - Computers and Geosciences 35(5): 978-992.

[7] Langhans, C., Nyman, P., Noske, P. J., Van der Sant, R. E. (2017): Post-fire hillslope debris flows: Evidence of a distinct erosion process. - Geomorphology 295(10): 55-75. 
[8] Lee, K., Jeong., S. (2018): Large deformation FE analysis of a debris flow with entrainment of the soil layer. - Computes and Geotechnics 96(4): 258-268.

[9] Lin, X. P., You, Y., Liu, J. F., Zhao, Y. B., Liu, S. L. (2013): Experiment study on channel deposition of viscous debris flow over erodible beds. - Journal of Mountain Science 31(3): 327-333.

[10] Liu, J. F., Ou, G. Q., You, Y. (2006): Experimental research on velocity and deposition mode of debris flow. - Research of Soil and Water Conservation 13(1): 120-121.

[11] Ma, Z. Y., Zhang, J., Liao, H. J. (2007): Numerical simulation of viscous debris flow block engineering. - Rock and Soil Mechanics 28(S1): 389-392.

[12] Prieto, J. A., Journeay, M., Acevedo, A. B., Arbelaez, J. D., Ulmi., M. (2018): Development of structural debris flow fragility curves (debris flow buildings resistance) using momentum flux rate as a hazard parameter. - Engineering Geology 239(18): 144157.

[13] Shu, A. P., Fei, X. J. (2003): Calculation for velocity and discharge of the viscous debris flow. - Journal of Sediment Research 47(3): 3-11.

[14] Ugelvig, S. V., Egholm, D. L. (2018): The influence of basal-ice debris on patterns and rates of glacial erosion. - Earth and Planetary Science Letters 490(5): 110-121.

[15] Wang, Z. Y. (2001): Experimental study on debris flow head and the energy theory. Journal of Hydraulic Engineering 45(3): 18-26.

[16] Zhang, W. S., Zhao, Y. X., Cui, P., Peng, H., Chen, X. J. (2012): Two-dimensional numerical model for debris flow motion and gully bed evolution. - Science of Soil and Water Conservation 10(1): 1-5.

[17] Zhang, N. T., Matsushima. (2018): Numerical investigation of debris materials prior to debris flow hazards using satellite images. - Geomorphology 308(5): 54-63.

[18] Zhao, J. K., Wang, D., Chen, J. H. (2015): Experimental study on slope sliding and debris flow evolution with and without barrier. - Water Science and Engineering 8(1): 68-77.

[19] Zhou, J., Li, Y. X., Zhang, J., Jia, M. C. (2013): Macro-Meso Research of soil deformation mechanism of debris flow on slope prevention. - Chinese Journal of Rock Mechanics and Engineering 32(5): 1001-1008. 